\title{
Morphometric characteristics of the optic canal and the optic nerve
}

\author{
M. Radunovic ${ }^{1}$, B. Vukcevic ${ }^{1}$, N. Radojevic ${ }^{2}$, N. Vukcevic ${ }^{1}$, N. Popovic ${ }^{1}$, A. Vuksanovic-Bozaric \\ ${ }^{1}$ Faculty of Medicine, University of Montenegro, Podgorica, Montenegro \\ ${ }^{2}$ Department of Forensic Medicine, Clinical Centre of Montenegro, Podgorica, Montenegro
}

[Received: 19 March 2018; Accepted: 25 June 2018]

\begin{abstract}
Background: The optic nerve (ON), a major component of the visual system, is divided into four segments: the intrabulbar (IB), the intraorbital (IO), the intracanalicular (ICn) and the intracranial (ICr). The ICr ends with the two nerves partially decussating in the optic chiasm (OCh). The purpose of this study is to provide a detailed description of the dimensions of the $\mathrm{OC}$ (the diameter and the surface area of its foramina and the central segment, as well as the length of the OC and the thickness of its walls) as well as the ON (the length of the ON segments, the diameter of the ICn segment of the ON, the angle of decussation in the OCh, as well as the distance between the two ON at the cranial foramen of the OC). Materials and methods: The acquired data was then used to estimate the volume of the OC and the ICn segment of the ON. The morphometric research was performed on 25 cadavers ( 17 male and 8 female) and 30 skulls.

Results: The surface area of the central segment of the OC was significantly smaller than the cranial foramen $(p=0.02)$ and the orbital foramen $(p=0.009)$. The inferior wall of the OC was significantly shorter than the other OC walls $(p<0.0001)$. The 10 segment of the ON was the longest, where the difference to the ICn and ICr was statistically significant $(p<0.0001)$. The surface area of the $O N$ at the cranial foramen was significantly larger than the surface area at the central segment of the OC $(p=0.02)$ and orbital foramen $(p<0.0001)$. The difference between the surface areas of the $\mathrm{ON}$ at the orbital foramen and the central segment of the OC was also statistically significant $(p=0.01)$. The estimated volume of the OC was calculated to be $190.72 \mathrm{~mm}^{3}$, and the volume of the ICn segment of the ON was estimated to be $50.25 \mathrm{~mm}^{3}$.

Conclusions: It is absolutely crucial to open the central segment of the OC when decompressing the $\mathrm{ON}$, due to the narrowing of the $\mathrm{OC}$ in this segment. (Folia Morphol 2019; 78, 1: 39-46)
\end{abstract}

Key words: decompression, morphometry, optic canal, optic nerve

\section{INTRODUCTION}

The optic nerve $(\mathrm{ON})$ is the second cranial nerve representing a major component of the visual system. The ON is divided into four segments: the intrabulbar (IB), the intraorbital (IO), the intracanalicular (ICn) and the intracranial $(\mathrm{ICr})$. The retina and the $\mathrm{ON}$ arise from the neuroectoderm [19]. The ON is approximately
$40 \mathrm{~mm}$ long [8]. The IB segment of the ON is located inside the eye bulb, from which the 10 segment arises, which itself extends to the optic canal (OC). The OC passes through the root of the lesser wing of the sphenoid bone, connecting the middle cranial fossa to the orbit. The length of the $\mathrm{OC}$ measures approximately $5 \mathrm{~mm}$ [15]. The superior wall of the $O C$ is 
formed by a thin bony lamina separating the $\mathrm{OC}$ from the anterior cranial fossa. The $\mathrm{OC}$ is bounded laterally and inferiorly by the anterior clinoid process of the lesser wing [13]. Medially, the OC comes into contact with the sphenoid sinus and the sphenoethmoidal air cells [11]. The ICn part of the OC travels between the orbital and the cranial foramen of the $\mathrm{OC}$, joined by the ophthalmic artery. The entrance of the ON into the middle cranial fossa marks the beginning of its $\mathrm{ICr}$ segment, usually $10 \mathrm{~mm}$ in length. The $\mathrm{ICr}$ ends with the two nerves partially decussating in the optic chiasm (OCh) [22]. The proximity of the bone to nerve fibers in the $O C$ is a locus minoris resistentiae in the event of injury or any expansive processes affecting the ON. Decompression of the ON is one of the most common neurosurgical procedures in the OC [7]. Being highly knowledgeable of the anatomy of the $\mathrm{OC}$ and the $\mathrm{ON}$ is necessary in order to diagnose and treat diseases affecting the $\mathrm{ON}$ and the brain, paranasal sinuses, as well as the bones of the skull. The preoperative diagnostic approach to the $\mathrm{OC}$ and $\mathrm{ON}$ is based on modern radiological techniques, such as magnetic resonance imaging and computed tomography, while anatomical research methods (i.e., morphometry) can provide novel ideas in surgery of the OC and the ON.

The main purpose of this study is to provide a detailed description of the dimensions of the $O C$ and the ON. The specific aims of this study are to evaluate the size of the $\mathrm{OC}$ by measuring the diameter and the surface area of its foramina and the central segment, as well as the length of the $O C$ and the thickness of its walls. The following measures of the ON were taken: the length of the ON segments, the diameter of the $\mathrm{ICn}$ segment of the ON, the angle of decussation in the OCh, as well as the distance between the two $\mathrm{ON}$ at the cranial foramen of the OC. The acquired data was then used to estimate the volume of the $O C$ and the ICn segment of the ON. Such a description of the morphometric characteristics of the $O C$ and the ON helps to expand what is known of the anatomy of the visual system, providing better orientation in surgery of this region.

\section{MATERIALS AND METHODS}

For this study, morphometric research of the ON was conducted on 25 cadavers during autopsies at the Institute of Pathology, Faculty of Medicine, University of Belgrade. The research was carried out on 17 male and 8 female bodies, of 46 to 78 years of age (the average age was 67.3). There was no evidence of brain pathology. The autopsy was performed no later than 10-24 $\mathrm{h}$ after the death. During the removal of the brain from the skull, the ONs were cut at the cranial foramina of their OCs. Subsequent to this, both internal carotid arteries were transected, as well as the pituitary stalk, the oculomotor nerves and the attachment of the tentorium. Finally, the cerebellum was released by cutting the remaining cranial nerves, the vertebral arteries, and the spinal cord. The brain was immersed in saline. In order to access the ICn and the IO segment, as well to make precise measurements, the following approach was used: after the removal of the orbital roof, the periorbita was opened and the contents of the orbit were removed along with the adipose tissue. The ON was transected near the wall of the eye bulb and the superior wall of the OC was removed. The ICn segment was transected at the orbital foramen of the $\mathrm{OC}$ in order to separate it from the $\mathrm{IO}$ segment. The length of the $\mathrm{ICr}$ segment was measured on the removed brain, while the length of the ICn and the IO segment was measured in situ. In addition, the diameter of the ICn segment was measured at the orbital and cranial foramen and in the central segment of the OC. The measurements were taken by a Vernier caliper (Fig. 1).

The morphometric research of the OC was performed on 30 skulls from the collection of the Institute of Anatomy, Faculty of Medicine, University of Belgrade (Fig. 2). The measurements were taken by an ocular micrometer from a Leica MZ6 stereomicroscope and by a Vernier caliper. All measurements (including both the ON and the OC) were taken by three researchers independently, with the intra-class correlation coefficient over 0.90 with a $95 \%$ confidence interval $(\mathrm{Cl})$.

The surface areas of the foramina and the central segment of the $\mathrm{OC}$ were calculated using the mathematical formula for the surface area of an ellipse: $a b \pi$. The surface area of the ICn segment of the ON was calculated using the mathematical formula for the surface area of a circle: $r^{2} \pi$. The volume of the $O C$ and the ICn segment was estimated using the mathematical formula for the volume of a cone frustum: $\pi h / 3\left(R^{2}+R r+r^{2}\right)$. The calculations are explained in the following results section of this paper.

The standard statistical protocol for descriptive statistics was used, including a t-test for independent samples at $95 \% \mathrm{Cl}$. The acquired data is laid out here in tables and figures. 

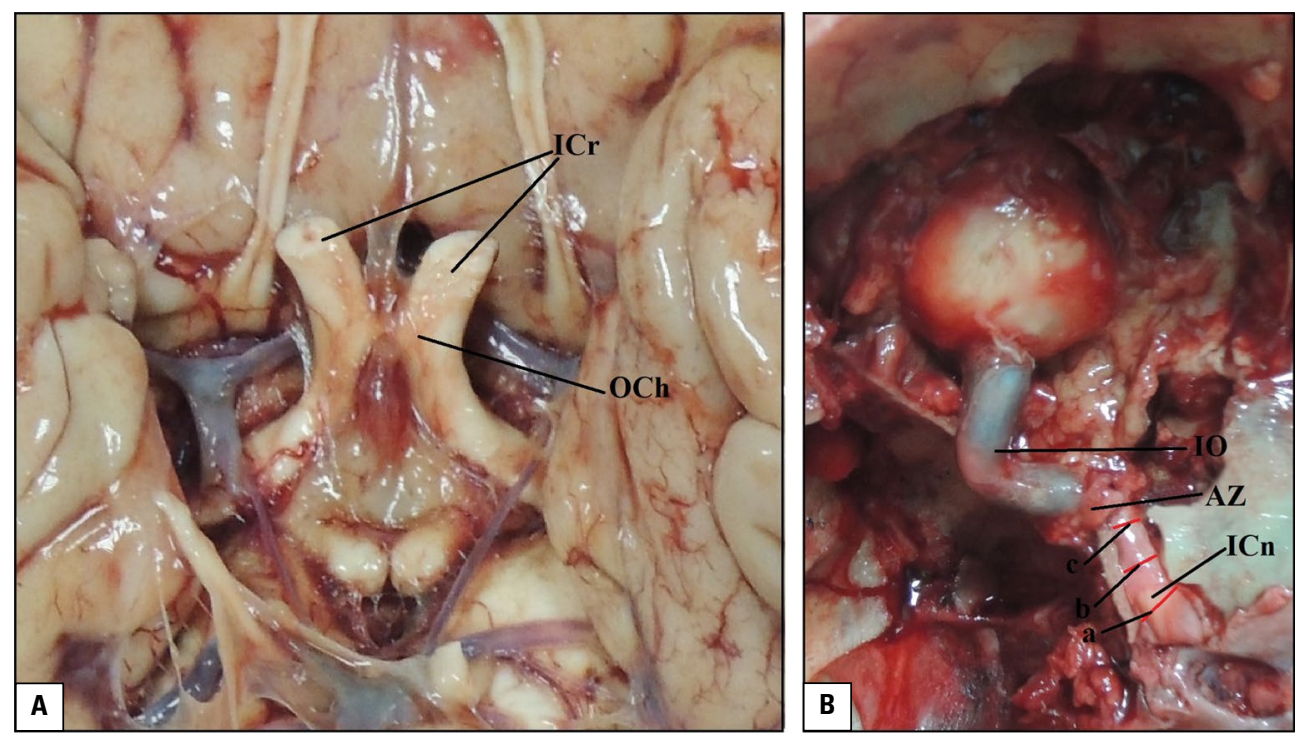

Figure 1. The optic nerve and the optic chiasm; $A$. The brain with the optic chiasm (OCh) and the intracranial (ICr) segment of the optic nerve (ON); B. The left $\mathrm{ON}$ in situ. 10 represents the intraorbital segment of the $\mathrm{ON}$. ICn represents the intracanalicular segment of the ON. AZ represents the remnants of the annulus of Zinn. $a, b$, and $c$ mark the diameters of the $0 \mathrm{~N}$ at the cranial, central and orbital segment of the optic canal, respectively.

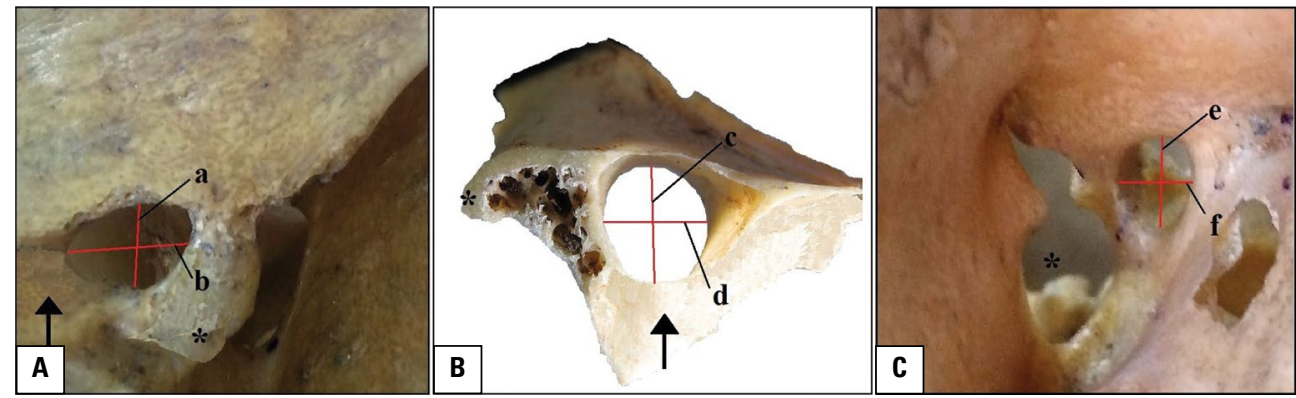

Figure 2. The right optic canal $(\mathrm{OC})$; $\mathrm{A}$. View from the middle cranial fossa. a and $b$ represent the height and width of the cranial foramen of the $\mathrm{OC}$, respectively. The asterisk marks the anterior clinoid process, and the arrow marks the body of the sphenoid bone; $\mathbf{B}$. Anterior view to the section through the central segment of the $\mathrm{OC}$, with $\mathrm{c}$ and d representing its height and width, respectively. The asterisk marks the anterior clinoid process, and the arrow marks the wall of the sphenoid sinus; C. View from the orbit. $\mathrm{e}$ and $\mathrm{f}$ represent the height and width of the orbital foramen of the $\mathrm{OC}$, respectively. The asterisk marks the superior orbital fissure.

\section{RESULTS}

\section{Measurements of the optic canal}

The height and width of the orbital and cranial foramen of the $O C$, as well as its central part, are given in Table 1. According to the $t$-test, no statistically significant difference was found between the height and width of the right and left orbital foramen $(p=0.78)$, as well as the height $(p=0.5)$ and the width ( $p=0.7)$ of the right and left cranial foramen. The same conclusion was reached when comparing the central segment of the right and left OC ( $p=0.76$ for the width and $p=0.75$ for the height). Therefore, the mean values of the right and left side were used in order to calculate the surface areas of the OC. The difference between the surface areas of the orbital and cranial foramen of the $\mathrm{OC}$ was found not to be statistically significant $(p=0.5)$, while the difference between the surface area of the orbital foramen and the central segment was found to be extremely significant $(p=0.009)$. Moreover, the difference between the surface areas of the cranial foramen and the central segment was also significant $(p=0.02)$.

Measuring the length of the $O C$ walls required determining their boundaries. The inferior and lateral wall terminate on the lesser wing's bone crest which separates the $O C$ from the superior orbital fissure. It 
Table 1. The range of the values of the optic canal foramina measurements. Mean values \pm standard deviation are given in parentheses

\begin{tabular}{lcc}
\hline Optic canal & Left & Right \\
\hline Orbital foramen width $[\mathrm{mm}]$ & $3.6-6.8(4.86 \pm 0.70)$ & $3.8-6.9(4.91 \pm 0.71)$ \\
Orbital foramen height $[\mathrm{mm}]$ & $3.5-6.9(5.38 \pm 0.68)$ & $3.4-6.8(5.43 \pm 0.71)$ \\
Cranial foramen width [mm] & $3.9-5.5(4.85 \pm 0.49)$ & $4.2-5.6(4.90 \pm 0.51)$ \\
Cranial foramen height $[\mathrm{mm}]$ & $3.7-6.6(4.55 \pm 0.56)$ & $3.6-6.2(4.65 \pm 0.6)$ \\
Central part width $[\mathrm{mm}]$ & $3.9-5.1(4.35 \pm 0.62)$ & $4.0-5.2(4.40 \pm 0.64)$ \\
Central part height $[\mathrm{mm}]$ & $3.2-6.1(4.25 \pm 0.61)$ & $3.4-5.9(4.3 \pm 0.6)$ \\
Surface area of orbital foramen $\left[\mathrm{mm}^{2}\right]$ & $19.72 \pm 2.25$ & \\
Surface area of cranial foramen $\left[\mathrm{mm}^{2}\right]$ & $19.36 \pm 1.87$ & \\
Surface area of central segment $\left[\mathrm{mm}^{2}\right]$ & $18.13 \pm 2.3$ & \\
\hline
\end{tabular}

Table 2. The range of the values of the optic canal walls' measurements. Mean values \pm standard deviation are given in parentheses

\begin{tabular}{lc}
\hline Medial wall length [mm] & $10.34-15.26(13.43 \pm 2.06)$ \\
Superior wall length [mm] & $10.11-14.72(12.48 \pm 3.24)$ \\
Inferior wall length [mm] & $5.26-7.48(6.41 \pm 1.56)$ \\
Lateral wall length [mm] & $6.34-9.37(8.36 \pm 1.83)$ \\
Medial wall thickness [mm] & $0.28-0.8(0.34 \pm 0.08)$ \\
Superior wall thickness [mm] & $0.27-0.34(0.29 \pm 0.06)$ \\
Inferior wall thickness [mm] & \\
42 cases (70\%): & $0.21-0.29(0.26 \pm 0.06)$ \\
18 cases (30\%): & $2.6-3.2(2.9 \pm 0.16)$ \\
Lateral wall thickness [mm] & $2.9-3.4(3.0 \pm 0.2)$ \\
\hline
\end{tabular}

was decided that the sutures connecting the lesser wing to the frontal and ethmoidal bones were to be used as boundaries of the superior and medial wall. These results are provided in Table 2 . Given the fact that the difference in size of the foramina of the right and left OC was not statistically significant, it was then decided to display and analyse the range of the values of the OC walls' length and thickness as the average of both sides. The medial wall was the longest, followed by the superior and lateral wall, with the inferior wall being the shortest. There was a statistically significant difference in the length of the inferior wall compared to other walls ( $p<0.0001)$. The lateral wall was the thickest, followed by the medial and superior wall. The inferior wall was pneumatised in $70 \%$ of cases and compact in $30 \%$. The thickness of a pneumatised inferior wall was similar to the superior wall, while the compact form was thinner from the lateral wall only. Comparing the lateral wall thickness to the medial, superior and pneumatised infe- rior walls produced an extremely significant difference ( $p<0.0001)$. Ultimately, the lateral wall was significantly thicker than the compact inferior wall $(p=0.04)$.

\section{Measurements of the optic nerve}

As there was no statistically significant difference found between the measurements of the right and left $O N$, the decision was made to display and analyse the range of measurements as the average of both sides. The length of the $\mathrm{ICr}$ segment was defined as the distance from the central point of the OCh to the medial boundary of the ON at the cranial foramen of the OC. Measuring the length of the ICn segment proved to be a technical problem, due to the precise boundaries of the $\mathrm{OC}$, whose length also determines that of the ICn segment. Since the OC walls are of differing lengths, the length of the shortest, inferior wall was accepted as the length of the ICn segment. For this purpose, the results obtained from the research on the skulls was used, owing to the fact that the inferior wall of the $O C$ was covered by the $\mathrm{ON}$, impeding its measurement. The angle of the ON decussation was measured between the medial edges of the nerves. The distance between the ONs was measured between their medial edges at the cranial foramen of the $O C$ (Fig. 3). The length of the ICr and the IO segment, the angle of decussation and the distance between two ONs, as well as the accepted results for the $\mathrm{ICn}$, are given in Table 3 . The IO segment was the longest, where the difference to the ICn and ICr was statistically significant $(p<0.0001)$. Table 4 sets out the measured diameters of the ICn segment. The diameter grows from the orbital to the cranial foramen of the OC. The difference between the diameter of the $\mathrm{ON}$ at the cranial and the orbital 


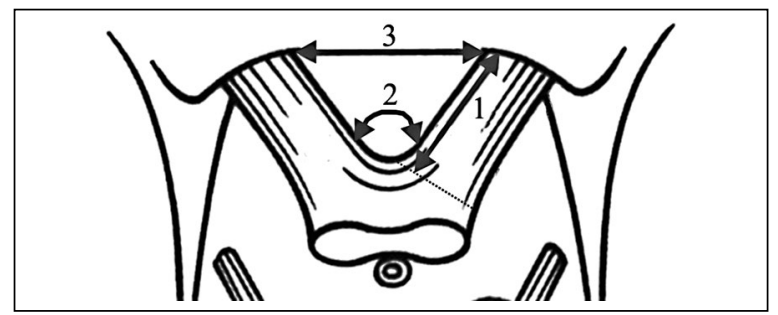

Figure 3. A schematic representation of the optic chiasm with the measurements taken; 1 - the length of the intracranial segment of the optic nerve; 2 - the angle of decussation of the two optic nerves; 3 - the distance between the medial edges of the optic nerves.

foramen was found to be statistically significant $(p=0.04)$; however, the difference between the diameter at the central segment of the $O C$ and at the cranial foramen was found not to be significant $(p=0.31)$, including the orbital foramen $(p=0.1)$. The surface area of the $\mathrm{ON}$ at the cranial and orbital foramina, as well as the central part of the $\mathrm{OC}$, was calculated by means of the mathematical formula for the surface area of a circle. The surface area of the ON at the cranial foramen was larger than the surface area at the central segment of the $O C$. This difference was found to be statistically significant $(p=0.02)$. There was also an extremely significant difference found between the surface areas at the cranial and orbital foramen $(p<0.0001)$. The difference between the surface areas at the orbital foramen and the central segment of the $O C$ was statistically significant $(p=0.01)$.

The estimated volume of the $\mathrm{OC}$ and the intracanalicular segment of the $\mathrm{ON}$

The volume of the $O C$ was estimated to be the volume of the two cone frustums, due to the narrowing of the $\mathrm{OC}$ in its central segment: the volume

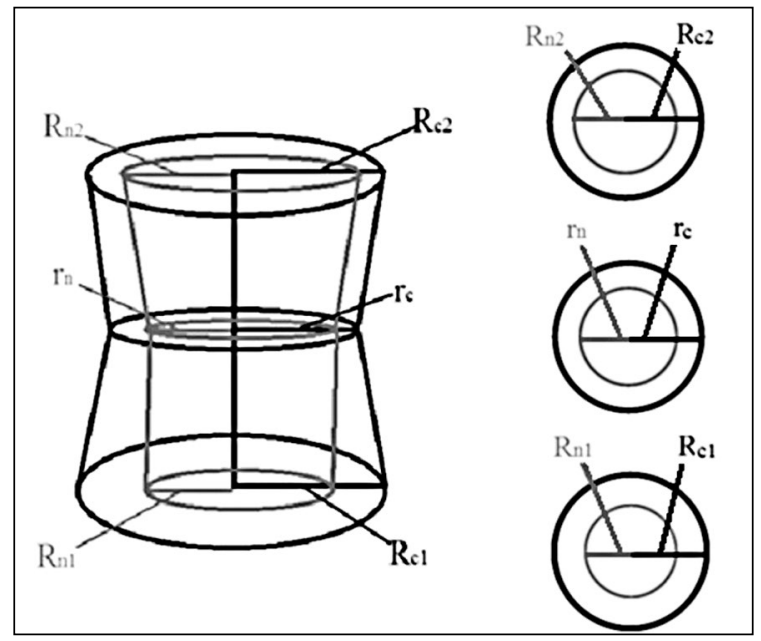

Figure 4. The ratio of the diameters of the optic canal and the optic nerve at the orbital and the cranial foramen, as well as the central segment of the optic canal; $R_{c 1}$ - the radius of the optic canal at its orbital foramen; $r_{c}$ - the radius of the optic canal at its central segment; $\mathrm{R}_{\mathrm{c} 2}$ - the radius of the optic canal at its cranial foramen; $R_{n 1}$ - the radius of the optic nerve at the orbital foramen of the optic canal; $r_{n}$ - the radius of the optic nerve at the central segment of the optic canal; $\mathrm{R}_{\mathrm{n} 2}$ - the radius of the optic nerve at the cranial foramen of the optic canal.

of the cone frustum between the cranial foramen to the central segment of the OC (V1) and the volume of the cone frustum between the central segment and the orbital foramen (V2) (Fig. 4). The mathematical formula for the volume of a cone frustum requires the radii of the two bases, as well as the height of that geometric shape. Even though the foramina and the central segment of the $\mathrm{OC}$ are not perfect circles, they were analyzed as such for the purpose of this calculation. Therefore, the mathematical formula was used for the surface area of a circle to calculate their radii from their previously calculated surface areas.

Table 3. The range of the values of the optic nerve measurements. Mean values \pm standard deviation are given in parentheses

\begin{tabular}{lccc}
\hline Optic nerve & Intracranial segment & Intracanalicular segment & Intraorbital segment \\
\hline Length $[\mathrm{mm}]$ & $7.2-14.1(11.01 \pm 1.82)$ & $5.26-7.48(6.41 \pm 1.56)$ & $22.7-33.4(27.2 \pm 2.43)$ \\
Angle of decussation of the optic nerves $\left[^{0}\right]$ & $50-80\left(66.27 \pm 8.20^{\circ}\right)$ & & \\
Distance between the two optic nerves $[\mathrm{mm}]$ & $6.3-14.1(11.59 \pm 1.44)$ & & \\
\hline
\end{tabular}

Table 4. The diameters and surface areas of the intracanalicular segment of the optic nerve. Mean values \pm standard deviation are given

\begin{tabular}{lccc}
\hline Intracanalicular segment of the optic nerve & $\begin{array}{c}\text { At the orbital } \\
\text { foramen }\end{array}$ & $\begin{array}{c}\text { At the central part } \\
\text { of the optic canal }\end{array}$ & $\begin{array}{c}\text { At the cranial } \\
\text { foramen }\end{array}$ \\
\hline Diameter $[\mathrm{mm}]$ & $2.98 \pm 0.35$ & $3.16 \pm 0.43$ & $3.34 \pm 0.78$ \\
Surface area $\left[\mathrm{mm}^{2}\right]$ & $6.97 \pm 1.31$ & $7.84 \pm 1.20$ & $8.76 \pm 1.53$ \\
\hline
\end{tabular}


Table 5. The measurements of the optic canal obtained by authors in the literature. Mean values \pm standard deviation (where available) are given

\begin{tabular}{|c|c|c|c|c|c|c|}
\hline & $\begin{array}{l}\text { Chou et al. } \\
\text { (1995) }\end{array}$ & $\begin{array}{l}\text { Govsa et al. } \\
\text { (1998) }\end{array}$ & $\begin{array}{c}\text { Ozturk et al. } \\
\text { (1999) }\end{array}$ & $\begin{array}{l}\text { Akdemir et al. } \\
\text { (2004) }\end{array}$ & $\begin{array}{l}\text { Hart et al. } \\
\text { (2009) }\end{array}$ & $\begin{array}{c}\text { Kalthur et al. } \\
\text { (2015) }\end{array}$ \\
\hline Number of optic canals & 18 & 318 & 152 & 50 & 191 & 50 \\
\hline Medial wall length [mm] & $13.63 \pm 2.05$ & $\begin{array}{r}\text { rt: } 7.5 \pm 1.5 \\
\text { It: } 7.72 \pm 1.41\end{array}$ & $\begin{array}{l}\text { rt: } 10.7 \\
\text { It: } 10.5\end{array}$ & - & 14.8 & $9.10 \pm 1.46$ \\
\hline Lateral wall length [mm] & $8.78 \pm 1.56$ & $\begin{array}{l}\text { rt: } 6.48 \pm 1.61 \\
\text { lt: } 6.94 \pm 1.84\end{array}$ & $\begin{array}{l}\text { It: } 9.9 \\
\text { It: } 10.1\end{array}$ & - & 10.5 & $8.66 \pm 1.31$ \\
\hline Superior wall length [mm] & $12.17 \pm 4.05$ & $\begin{array}{l}\text { rt: } 6.66 \pm 1.57 \\
\text { lt: } 6.78 \pm 1.62\end{array}$ & $\begin{array}{l}\text { rt: } 7.8 \\
\text { It: } 8.1\end{array}$ & - & - & - \\
\hline Inferior wall length [mm] & $12.58 \pm 3.98$ & $\begin{array}{l}\text { rt: } 6.14 \pm 0.94 \\
\text { lt: } 6.29 \pm 1.44\end{array}$ & $\begin{array}{l}\text { rt: } 4.4 \\
\text { It: } 4.3\end{array}$ & - & - & - \\
\hline Orbital foramen width [mm] & - & $\begin{array}{l}\text { rt: } 4.93 \pm 0.73 \\
\text { It: } 4.55 \pm 0.72\end{array}$ & - & $\begin{array}{l}\text { rt: } 5.12 \pm 1.1 \\
\text { It: } 4.95 \pm 1.32\end{array}$ & 4.5 & $4.74 \pm 0.47$ \\
\hline Orbital foramen height [mm] & - & $\begin{array}{l}\text { rt: } 5.43 \pm 0.73 \\
\text { lt: } 5.25 \pm 0.89\end{array}$ & - & - & 4.9 & $5.70 \pm 0.76$ \\
\hline Cranial foramen width [mm] & - & $\begin{array}{l}\mathrm{rt}: 4.91 \pm 0.49 \\
\mathrm{lt}: 4.71 \pm 0.43\end{array}$ & - & $\begin{array}{l}\text { rt: } 7.431 .95 \\
\text { lt: } 7.382 .01\end{array}$ & 6.7 & $5.48 \pm 0.76$ \\
\hline Cranial foramen height [mm] & - & $\begin{array}{r}\text { rt: } 4.7 \pm 0.79 \\
\text { It: } 4.55 \pm 0.65\end{array}$ & - & - & 4.0 & $5.17 \pm 0.81$ \\
\hline
\end{tabular}

It - left; rt - right

The estimated radius of the orbital foramen was 2.50 $\mathrm{mm}$, the central segment, $2.40 \mathrm{~mm}$, and the cranial foramen, $2.48 \mathrm{~mm}$. The average of mean values of the OC walls' length was calculated, the result of which was subsequently divided by two. This value of $5.08 \mathrm{~mm}$ was used as the height of the cone frustums. The estimated volume of the cone frustum between the cranial foramen and the central segment of the OC was $94.96 \mathrm{~mm}^{3}$, while the estimated volume of the cone frustum between the central segment and the orbital foramen was $95.76 \mathrm{~mm}^{3}$. Therefore, the estimated volume of the $\mathrm{OC}$ was calculated to be $190.72 \mathrm{~mm}^{3}$.

The estimated volume of the ICn segment of the ON was calculated using the same formula. The complete ICn segment was observed as a single cone frustum, due to the stable growth of the nerve diameter from the orbital to the cranial foramen. The diameters of the ICn segment were divided by two in order to calculate the radii of the frustum, while the length of the ICn segment was the height of the frustum. The estimated volume of the ICn segment of the ON was calculated to be $50.25 \mathrm{~mm}^{3}$.

The ratio of the diameters of the $\mathrm{OC}$ and ICn segment of the $\mathrm{ON}$ is provided in Figure 2.

\section{DISCUSSION AND CONCLUSIONS}

This study investigates the $O C$ and the ON using morphometry as a standard anatomical research method. Modern diagnostic techniques adequately display the $\mathrm{OC}$ and the $\mathrm{ON}$ of the examined patient, while morphometric research possesses the advantage of providing a three-dimensional understanding of the relation of the $\mathrm{OC}$ to the $\mathrm{ON}$.

The results of the measurement are in accordance with the data from reports in the literature (Table 5). The study presented here shows the cranial foramen to be elliptical with its width longer than its length, which is similar to the outcomes found by Berge and Bergman [2], as well as the results published by Kalthur et al. [12]. The orbital foramen was found to have a longer height than width, which is in accordance to the results published by Berlis et al. [3], as well as Lang and Gehmann [16]. Although differing from our results, Chou et al. [5] reported the lateral wall of the $\mathrm{OC}$ to be the longest. According to their results, the central segment of the $O C$ is the narrowest as they insist that it is necessary to open this segment of the OC during ON decompression. In addition, their research claims that the central segment of the medial wall is the thinnest compared to other OC walls, 
Table 6. The measurements of the optic nerve obtained by authors in the literature. Mean values \pm standard deviation (where available) are given.

\begin{tabular}{lccccc}
\hline & $\begin{array}{c}\text { Renn et al. } \\
(\mathbf{1 9 9 1 )}\end{array}$ & $\begin{array}{c}\text { Peyman et al. } \\
(\mathbf{1 9 8 0 )}\end{array}$ & $\begin{array}{c}\text { Slavin et al. } \\
(\mathbf{1 9 9 4 )}\end{array}$ & $\begin{array}{c}\text { Govsa et al. } \\
\text { (1998) }\end{array}$ & $\begin{array}{c}\text { Ozturk et al. } \\
\text { (1999) }\end{array}$ \\
\hline Number of optic nerves & 100 & - & 40 & 116 & 16 \\
Intracranial segment length $[\mathrm{mm}]$ & 12.2 & 10 & - & - & - \\
Intracanalicular segment length [mm] & - & $4-10$ & $10.74 \pm 1.16$ & - & - \\
Intraorbital segment length [mm] & - & 33 & - & - & 76.8 \\
Angle of decussation of the optic nerves [0] & $50-80$ & - & - & $15.24 \pm 3.20$ & 14.1 \\
Distance between the two optic nerves [mm] & - & - & & & - \\
\hline
\end{tabular}

suggesting its vulnerability to trauma [5]. The central segment of the $\mathrm{OC}$ was found to be the narrowest, while Maniscalco and Habal [18] reported the distal segment of the $O C$ to have the smallest diameter in their study on 83 OCs. These authors reported the values of the thickness measurement to be slightly larger than our results. The difference exists because they measured the wall thickness on the cadavers, calculating the dura's thickness and the sinus mucosa together with the bone thickness [18]. Ozturk et al. [20] share the opinion that the distal segment of the $\mathrm{OC}$ is the narrowest.

The OC's development is dictated by the development of the anterior clinoid process. The first step in its creation is a cartilaginous foramen in the third month of foetal development. Thereafter, the cartilage ossifies and extends to the orbit. It the last 2 months of the foetus, the anterior clinoid process is fully developed, marking the end of the OC's development [14]. Variations in the shape of the OC have been described in the literature. During its embryological development, the $\mathrm{OC}$ is separated from the superior orbital fissure by a bone crest created by the fusion of two primordial processes. The lack of fusion of these two processes causes the cranial foramen of the OC to be duplicated $[4,6]$. The entire OC may also be duplicated [17]. These anomalies have not been observed in the material provided in this study. This study has not taken into account analyses of the anthropometric data of the bodies whose skulls were used for measurements; hence, any possible effects of the anthropometric parameters on the OC dimensions were unable to be calculated.

Table 6 presents literature reports on the measurements of the ON. Govsa et al. [9] performed a study on 116 cadavers, which found the distance between the two ONs to be larger than the ones of our study. The authors used the middle of the ONs as a reference point, while the medial boundaries were used in our study [9]. The angle of ON decussation that was measured for this study presented here is in accordance to the outcomes of the study conducted by Renn and Rhoton [23]. Research carried out here has concluded that the IO segment of the ON to be the longest, which is similar to data presented in the literature [21]. The ON diameter grew from the orbital to the cranial foramen of the OC. This growth in the diameter may be linked to fascicular fusion occurring in the $\mathrm{ON}$ on its way from the eye bulb to the OCh [22].

The ICn segment of the ON may be damaged due to nerve oedema, haematoma, injury to the neural microvasculature, cerebrospinal fluid circulation issues as well as direct damage from bone fragments in an OC fracture. The basic mechanism of damage to the ON is due to compression of the nerve fibers [1]. Traditional surgical approaches to the $O C$, such as the transcranial approach, are replaced by endoscopic-endonasal approach [25]. The endoscopic approach to the $O C$ requires adequate information on the degree of the OC's exposure to the sphenoidal and ethmoidal sinuses, as well as its medial wall thickness. A computed tomography scan may be used to determine the relation of the medial wall to the sinuses, thus enabling appropriate preoperative planning [10]. It is imperative to maintain visual function while operating on the $O C$ and $O N$, which makes the relation of the nerve to the canal walls an important detail in OC anatomy [24]. A new method was herein utilised to estimate the volume of the $O C$ and the ICn segment of the $\mathrm{ON}$ in order to describe their relation. Despite the fact that the estimated volume of the OC $\left(190.72 \mathrm{~mm}^{3}\right)$ was nearly 4 times the estimated volume of the ICn segment of the ON $\left(50.25 \mathrm{~mm}^{3}\right)$, it is necessary to take into account their relation in the central segment of the OC. The narrowing of the $\mathrm{OC}$ 
in its central segment decreases the distance between its walls and the $\mathrm{ON}$, making this point critical. Their close contact consequently explains why this segment of the ON is usually damaged in nerve oedema or subarachnoid haemorrhage. It is concluded that it is absolutely crucial to open this segment of the OC when decompressing the ON. Knowing precisely the microanatomic characteristics of the $\mathrm{OC}$ and $\mathrm{ON}$ is necessary not only in order to diagnosis correctly and provide adequate treatment, but to prevent intraoperative neurovascular injury as well.

\section{REFERENCES}

1. Akdemir G, Tekdemir I, Altin L. Transethmoidal approach to the optic canal: surgical and radiological microanatomy. Surg Neurol. 2004; 62(3): 268-74; discussion 274, doi: 10.1016/j.surneu.2004.01.022, indexed in Pubmed: 15336879.

2. Berge JK, Bergman RA. Variations in size and in symmetry of foramina of the human skull. Clin Anat. 2001; 14(6): 406-413, doi: 10.1002/ca.1075, indexed in Pubmed: 11754234.

3. Berlis A, Putz R, Schumacher M. Direct and CT measurements of canals and foramina of the skull base. Br J Radiol. 1992; 65(776): 653-661, doi: 10.1259/0007-1285-65-776653, indexed in Pubmed: 1393389.

4. Bourjat $P$, Bittighoffer $B$. [Radio-anatomical variants of the optic canal]. J Radiol. 1984; 65(10): 711-712, indexed in Pubmed: 6527341.

5. Chou PI, Sadun AA, Lee H. Vasculature and morphometry of the optic canal and intracanalicular optic nerve. J Neuroophthalmol. 1995; 15(3): 186-190, indexed in Pubmed: 8574366.

6. Choudhry R, Anand M, Choudhry S, et al. Morphologic and imaging studies of duplicate optic canals in dry adult human skulls. Surg Radiol Anat. 1999; 21(3): 201-205, indexed in Pubmed: 10431334.

7. Cook MW, Levin LA, Joseph MP, et al. Traumatic optic neuropathy. A meta-analysis. Arch Otolaryngol Head Neck Surg. 1996; 122(4): 389-392, indexed in Pubmed: 8600923.

8. Duke-Elder. System of Ophthalmology, Vol II. The anatomy of the visual system. Henry Kimpton, London 1961: 283-286.

9. Govsa F, Erturk M, Kayalioglu G, et al. Neuro-arterial relations in the region of the optic canal. Surg Radiol Anat. 1999; 21(5): 329-335, doi: 10.1007/s00276-999-0329-x, indexed in Pubmed: 10635097.

10. Hart CK, Theodosopoulos PV, Zimmer LA. Anatomy of the optic canal: a computed tomography study of endoscopic nerve decompression. Ann Otol Rhinol Laryngol. 2009;
118(12): 839-844, doi: 10.1177/000348940911801203, indexed in Pubmed: 20112517.

11. Ji Y, Qian Z, Dong Y, et al. Quantitative morphometry of the orbit in Chinese adults based on a three-dimensional reconstruction method. J Anat. 2010; 217(5): 501-506, doi: 10.1111/j.1469-7580.2010.01286.x, indexed in Pubmed: 20807268.

12. Kalthur S, Periyasamy R, Kumar S, et al. A morphometric evaluation of the optic canal: Comparative study between computerized tomographic study and direct anatomic study. SJMMS. 2015; 3(3): 204, doi: 10.4103/1658631x.161997.

13. Karakaş $\mathrm{P}$, Bozkir MG, Oguz O. Morphometric measurements from various reference points in the orbit of male Caucasians. Surg Radiol Anat. 2002; 24(6): 358-362, doi: 10.1007/s00276-002-0071-0, indexed in Pubmed: 12652362.

14. Kier EL. Embryology of the normal optic canal and its anomalies. An anatomic and roentgenographic study. Invest Radiol. 1966; 1(5): 346-362, indexed in Pubmed: 5970634.

15. Lang J. Clinical anatomy of the posterior fossa and its foramina. Georg Thieme Verlag, Stuttgart-New York 1991: 82-85.

16. Lang J, Gehmann G. Formenentwicklung des canalis opticus, seine masse und einstellung zu den schadelebenen. Verh Anat Ges. 1976; 70: 567-574.

17. Mağden A, Kaynak S. Bilateral duplication of the optic canals. Ann Anat. 1996; 178(1): 61-64, doi: 10.1016/ s0940-9602(96)80013-6.

18. Maniscalco J, Habal M. Microanatomy of the optic canal. J Neurosurg. 1978: 402-406, doi: 10.3171/jns. 1978.48.3.0402.

19. O'Rahilly R, Muller F. Human embryology \& teratology. Wiley - Liss, New 2001: 395-414.

20. Oztürk A, Bozbuğa M, Bayraktar B, et al. Surgical anatomy and morphometric analysis of the optico-chiasmatic apparatus, optic canal and sphenoid ridge. Okajimas Folia Anat Jpn. 1999; 75(6): 319-322, indexed in Pubmed: 10217950.

21. Peyman G, Sanders D, Goldberg M. Principles and practice of ophthalmology. W.B. Saunders Co, Philadelphia - Tokyo 1980: 3-87.

22. Radunović M, Vitosević Z, Cetković M, et al. Morphometric analysis of the fascicular organisation of the optic nerve. Vojnosanit Pregl. 2015; 72(2): 132-135, doi: 10.2298/ vsp1502132r, indexed in Pubmed: 25831904.

23. Renn W, Rhoton A. Microsurgical anatomy of the sellar region. J Neurosurg. 1975: 288-298, doi: 10.3171/ jns.1975.43.3.0288.

24. Slavin KV, Dujovny M, Soeira G, et al. Optic canal: microanatomic study. Skull Base Surg. 1994; 4(3): 136-144, indexed in Pubmed: 17171163.

25. Wohlrab TM, Maas S, de Carpentier JP. Surgical decompression in traumatic optic neuropathy. Acta Ophthalmol Scand. 2002; 80(3): 287-293, indexed in Pubmed: 12059868. 